\title{
The ten cytological races of the Scilla autumnalis species complex
}

\author{
H. E. VAUGHAN* $\dagger$, S. TAYLOR $\ddagger$ and J. S. PARKER $\ddagger \S$ \\ $\lceil$ School of Biological Sciences, University of East Anglia, Norwich NR4 7TJ and $\ddagger$ Department of Botany, University \\ of Reading, Whiteknights, P.O. Box 217, Reading RG6 2AH, U.K.
}

\begin{abstract}
Scilla autumnalis, a bulbaceous perennial member of the Liliaceae, is widespread throughout much of Europe and North Africa. So far it has been classified as a single species, primarily on morphological grounds. This paper reports 10 cytologically distinct races of the plant present over the range of distribution, and hypothesizes the existence, at least at some stage of the evolution of the complex, of two additional races. At least five distinct genomes are described, involving chromosomal rearrangements, changes in DNA amount and three levels of ploidy. A picture of the evolutionary relationships of the cytotypes is suggested.
\end{abstract}

Keywords: C-value paradox, cryptic species, evolution, geographical distribution, karyotype change, Scilla autumnalis.

\section{Introduction}

Cryptic species complexes are groups of closely related species that are difficult or impossible to distinguish by morphological traits. Such complexes have been described in a number of taxa, perhaps most notably invertebrates (Collins \& Paskewitz, 1996; Knio et al., 1996), but also in vertebrate and plant systems (Coates, 1992; Daugherty et al., 1994). Cryptic species have been identified in some cases by careful morphological analysis, DNA or allozyme analysis, karyotype change or chromosomal inversions. The liliaceous Scilla autumnalis has been classified as a single species on morphological grounds. In this paper we describe the karyotypes and nuclear DNA contents of plants from different locations.

The C-value paradox is the lack of correlation between nuclear DNA content and organismal complexity. It is particularly noticeable in some amphibians and several orders of higher plants, which can have surprisingly large nuclear genomes compared to seemingly closely related or more complex taxa (Nei, 1987; Bharathan et al., 1994). In this paper we compare nuclear DNA content in specimens of $S$. autumnalis from across the range, and consider changes in $\mathrm{C}$-value brought about by

\footnotetext{
*Correspondence. E-mail: h.e.vaughan@uea.ac.uk §Present address: University of Cambridge Botanic Gardens, Cory Lodge, Bateman Street, Cambridge CB2 1JF, U.K.
}

change in chromosome size as well as by polyploidization.

Polyploidy is widespread throughout the plant kingdom, and can occur naturally within and between taxa. It can bring about reproductive isolation in a single step. The concept of reproductive isolation - both pre- and postfertilization - is also considered with respect to other mechanisms. Such isolation in sympatry or allopatry could give rise to speciation. Stebbins has suggested that polyploids may be better at colonizing new territories than diploids (Stebbins, 1971). We describe the pattern of distribution of diploid and polyploid populations of $S$. autumnalis over Europe and North Africa and consider possible historical patterns of hybridization and colonization.

The possibility of environmental selection for different races is considered, with reference to other work on higher plants. The geographical range of the plant is vast, encompassing a wide variety of environments. Suggestions are made for the presentday distribution of karyotypes, with reference to possible glacial refugia, expansion and drift. The phylogeography of many temperate species has been fairly well characterized (Mayr \& O'Hara, 1986; Cooper et al., 1995). Current knowledge about locations of glacial refugia, and analysis of organismal diversity have helped elucidate geographical pathways of species expansion after the last Ice Age (Mayr \& O'Hara, 1986; Cooper et al., 1995). Our data from the $S$. autumnalis species complex are 
compared with current theories involving several refugia in Southern Europe, and routes of expansion from those refugia.

\section{Materials and methods}

Actively growing root tips were removed from plants and treated with 0.05 per cent colchicine for $3 \mathrm{~h}$. They were fixed overnight in ethanol:glacial acetic acid $3: 1$, then stored at $-20^{\circ} \mathrm{C}$. Standard Feulgen staining was performed and the roots tapped out in 2 per cent lactopropionic orcein.

DNA standards were calculated by microdensitometry, comparing Feulgen-stained mitotic prophase preparations (4C) with those of Vicia faba. Values are given for $2 \mathrm{C}$ nuclei.

\section{Results}

\section{The genomes of the $\mathrm{S}$. autumnalis complex}

The $B^{7}$ genome The $\mathrm{B}^{7}$ haploid set is made up of seven distinct chromosomes, five of which are acrocentric (Fig. 1). Pair 4 is the most acrocentric, with an arm ratio of $\approx 1: 5.1$. The other four acrocentrics (pairs 1,2,5 and 6) have arm ratios close to $1: 2$ but differ in overall length. Chromosome 7 is the smallest chromosome in the complement and is metacentric. Chromosome 3 is submetacentric, with an arm ratio of $1: 1.7$. This is the chromosome bearing the nucleolar-organizing region (NOR), which is a conspicuous secondary constriction in the long arm about a third of the way from the centromere.

The chromosomes of the $\mathrm{B}^{7}$ genome range from about $3-8 \mu \mathrm{m}$ in length at colchicine-metaphase, and have a mean width of $1.38 \mu \mathrm{m}$. The total length of the haploid complement is $32.1 \mu \mathrm{m}$.

The A genome The chromosomes of this genome show an overall similarity to $\mathrm{B}^{7}$, although they are larger (Fig. 1). There are seven pairs of chromosomes, five of which are acrocentric. Four have an arm ratio of about $1: 2$, whereas chromosome 4 has an arm ratio of $1: 4.3$. Chromosome 4 is slightly less acrocentric than its presumptive homoeologue in the $\mathrm{B}^{7}$ genome. Chromosome 3, again bearing the NOR, is slightly more metacentric (arm ratio $1: 1.3$ ) than its $\mathrm{B}^{7}$ homoeologue although the NOR is in a similar relative position along its long arm. The ratio of the centromere/NOR distance to the remainder of the long arm is $1: 2.8$ in the A genome, compared to $1: 2.7$ in the $\mathrm{B}^{7}$ genome. In allopolyploids, this secondary constriction of the NOR is absent (Vaughan et al., 1993; Fig. 2). Chromosome 7 is (a)

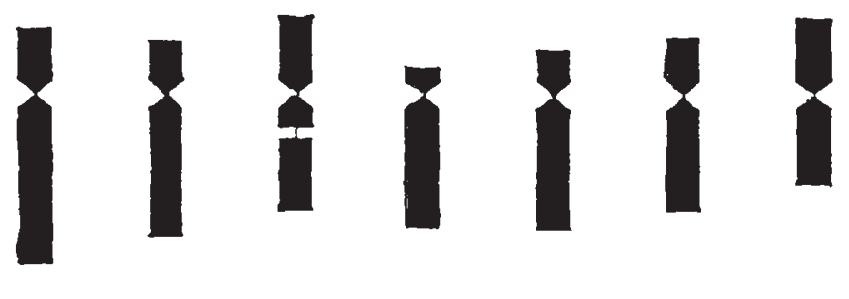

(b)

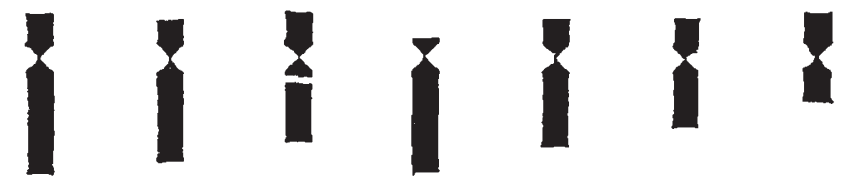

(c)

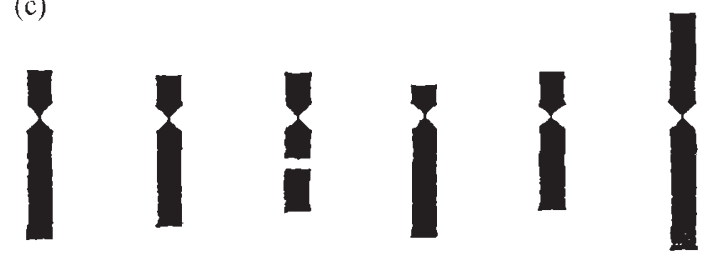

(d)

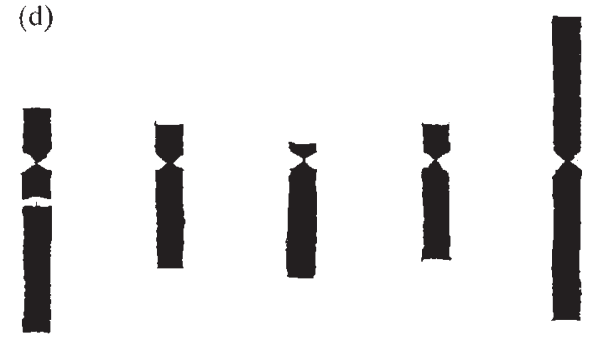

Fig. 1 The diploid karyotypes of Scilla autumnalis. Idiograms of the haploid set of chromosomes of each of the diploid genomes are shown: (a) the A genome; (b) the $\mathbf{B}^{7}$ genome; (c) the $\mathrm{C}^{6}$ genome; (d) the $\mathrm{B}^{5}$ genome. Positions of nucleolar-organizing regions (NORs) are indicated by a break in the long arm of chromosome 3 in genomes $A, B^{7}$ and $\mathrm{C}^{6}$, and in the fusion chromosome $1-3$ in genome $\mathbf{B}^{5}$.

slightly less metacentric than its $\mathrm{B}^{7}$ homoeologue (arm ratio $1: 1.16$ ) and is large, approaching the size of chromosome 3 . In general, the A genome is more symmetrical than the $\mathrm{B}^{7}$ genome.

Thus there are some differences in the chromosomes of the $\mathrm{A}$ and $\mathrm{B}^{7}$ genomes, but in general

(C) The Genetical Society of Great Britain, Heredity, 79, 371-379. 


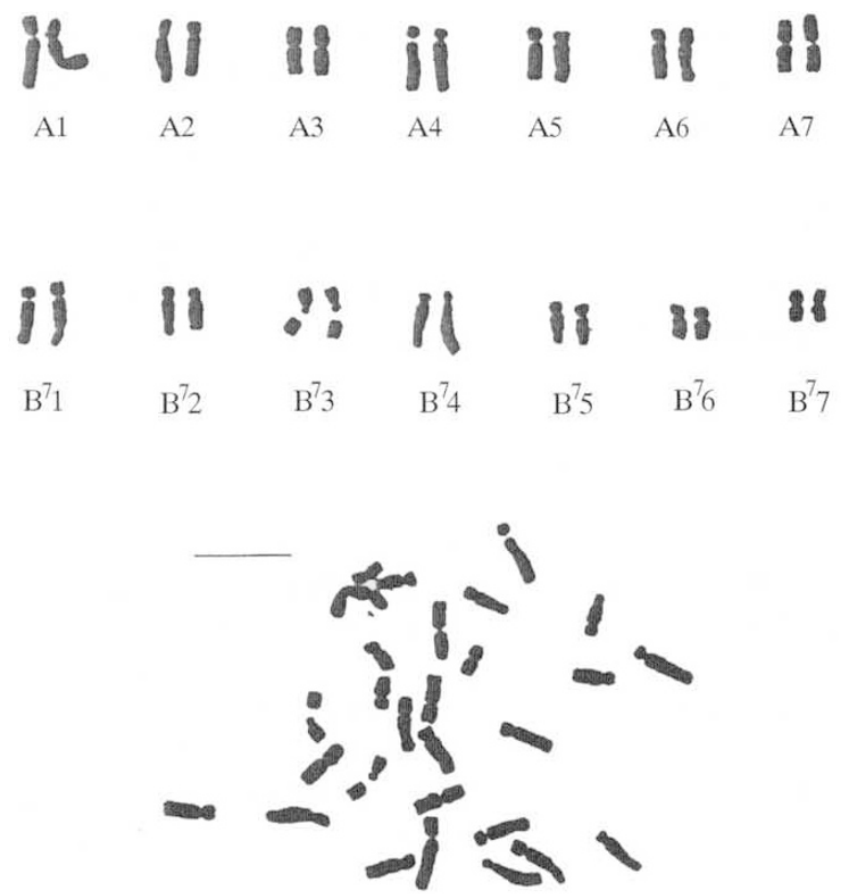

Fig. 2 Scilla autumnalis allotetraploid $\mathrm{AAB}^{7} \mathrm{~B}^{7}$ : c-metaphase cell and karyotype. NORs are present only in the smaller, $\mathrm{B}^{7}$ genome. Bar represents $10 \mu \mathrm{m}$.

presumptive homoeologues tend to be identifiable. There is an overall increase in length of $11.3 \mu \mathrm{m}$ to the haploid genome, and an increase in width; the mean width of A chromosomes is $1.68 \mu \mathrm{m}$. The total increase in DNA amount is 68 per cent.

The $C^{6}$ genome There are six chromosomes in the haploid set. Chromosomes of this genome differ from those of $\mathrm{B}^{7}$ in that there is an increase in DNA amount of 28 per cent and a complex rearrangement of chromosomes 6 and 7 (Fig. 1). In the $\mathrm{C}^{6}$ genome, fusion has given rise to a submetacentric chromosome $6 / 7$ (arm ratio $1: 1.35$ ), which is the largest in the complement. This is a complex fusion, in which the short arm and proximal part of the long arm are homoeologous with chromosome six of the $\mathrm{B}^{7}$ genome, and the distal part of the long arm is homoeologous with chromosome seven of the $\mathrm{B}^{7}$ genome. The rearrangement is deduced from our observations of metaphase I figures during meiosis. Again chromosomes.1, 2 and 5 are acrocentric, with arm ratios of $1: 2$. Chromosome 4 is more acrocentric, with an arm ratio of $\approx 1: 5$. Chromosome 3 , carrying the NOR, is somewhat more acrocentric than its $B^{7} 3$ homoeologue, with an arm ratio of about $1: 2$. The ratio of the distances centromere/ NOR to NOR/telomere is $1: 1.17$.
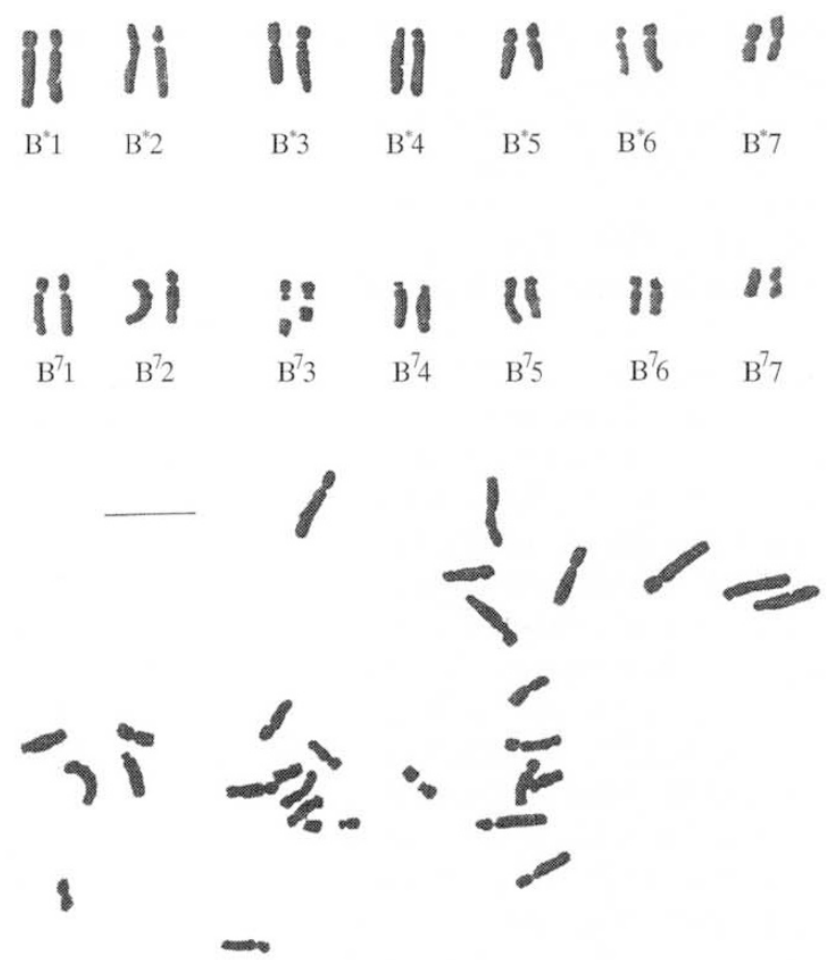

Fig. 3 Scilla autumnalis allotetraploid $\mathrm{B}^{7} \mathrm{~B}^{7} \mathrm{~B}^{*} \mathrm{~B}^{*}$ : c-metaphase cell and karyotype. Both NORs of the $\mathrm{B}^{7}$ genome are visible, but only one of the homologues of chromosome 3 in the $\mathrm{B}^{*}$ genome shows a single faint nucleolar constriction. Chromosome 3 is more acrocentric in the $\mathrm{B}^{*}$ genome than in the $\mathrm{B}^{7}$ in this individual. Bar represents $10 \mu \mathrm{m}$.

The $B^{5}$ genome Two rearrangements differentiate this genome from $\mathrm{B}^{7}$. As with $\mathrm{C}$, one involves chromosomes 6 and 7; the other involves chromosomes 1 and 3 , the nucleolar organizing chromosome (Fig. 1). The 6/7 chromosome is similar in relative length to that in the $C^{6}$ genome, but more nearly metacentric. Fusion chromosome $1 / 3$ has an arm ratio of about $1: 3.7$, with the secondary constriction of the NOR situated at about one-third the length of the chromosome. The short arm and NOR are derived from chromosome 3 and the bulk of the long arm from chromosome 1 . There is no change in size or morphology of the other chromosomes of the complement with respect to $\mathrm{B}^{7}$, but the overall haploid length of the complement is $1.8 \mu \mathrm{m}$ shorter than $\mathrm{B}^{7}$, indicating some loss of chromosome material.

The $B^{*}$ genome The chromosomes of the $\mathrm{B}^{*}$ genome are similar in size and morphology to $\mathrm{B}^{7}$, but the chromosomes appear longer, with slightly 
altered arm ratios. The $\mathrm{B}^{*}$ genome has seven chromosomes in the haploid set. The mean chromosome width of this genome is $1.36 \mu \mathrm{m}$, with chromosomes ranging from 4 to $10 \mu \mathrm{m}$ in length. Chromosome 3 is submetacentric with a mean arm ratio of $1: 1.67$. The secondary constriction of the NO-chromosome $\mathrm{B}^{*} 3$ is usually absent (Fig. 3).

The $D$ genome The basic haploid set has either six or seven chromosomes. This is dependent on whether chromosomes 6 and 7 are present as single elements or as the fusion 6/7, similar to that mentioned above. In the remainder of the complement, chromosomes 1, 2 and 5 are acrocentric, with arm ratios of about $1: 2$ but varying in absolute length. Chromosome 3 , the nucleolar-organizing chromosome, is submetacentric with a mean arm ratio of $1: 1.75$. Chromosome 4 is again the most acrocentric, with a mean arm ratio of about $1: 4$. Chromosome 6, when present, is an acrocentric (arm ratio 1:2), whereas chromosome 7 is a small metacentric. The fusion chromosome $6 / 7$ has a mean arm ratio of about $1: 1.3$, about the same as that in the $\mathrm{C}$ genome.

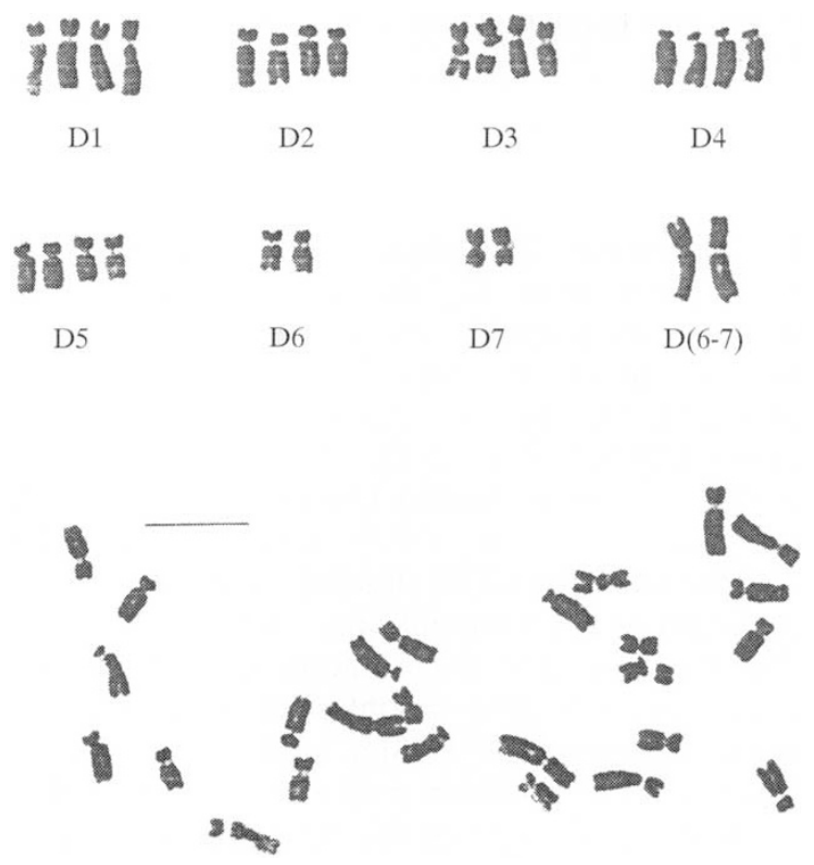

Fig. 4 A balanced Scilla autumnalis of cytotype DDDD, with $2 n=26$ : c-metaphase cell and karyotype. This tetraploid has four copies of chromosomes 1-5, and two copies of each of the three chromosomes 6, 7 and fusion 6-7. Two NORs are visible in this individual. Bar represents $10 \mu \mathrm{m}$.
In this genome the chromosomes tend in general to be at least as large as those of $\mathbf{B}^{7}$ and smaller than those of A. However, they vary tremendously in size compared to the other genomes. In addition, the morphology of the NOR-bearing chromosome is variable, with the secondary constriction sometimes absent, or occurring at any of a range of positions from 44-72 per cent of the distance along the long arm of chromosome 3 (Fig. 4).

\section{The $B^{6}$ genome and the relationship of genomes}

In order to propose a parsimonious picture of genome evolution in $S$. autumnalis, we must also postulate the existence of a further diploid genome, ${ }^{\prime} \mathbf{B}^{6}$, , as yet either undiscovered or extinct. In this genome, there would be a fusion chromosome 6/7, but no increase in DNA amount above the $\mathrm{B}^{7}$ level. The formation of fusion chromosome $6 / 7$ is a complex event, involving at least three breakages

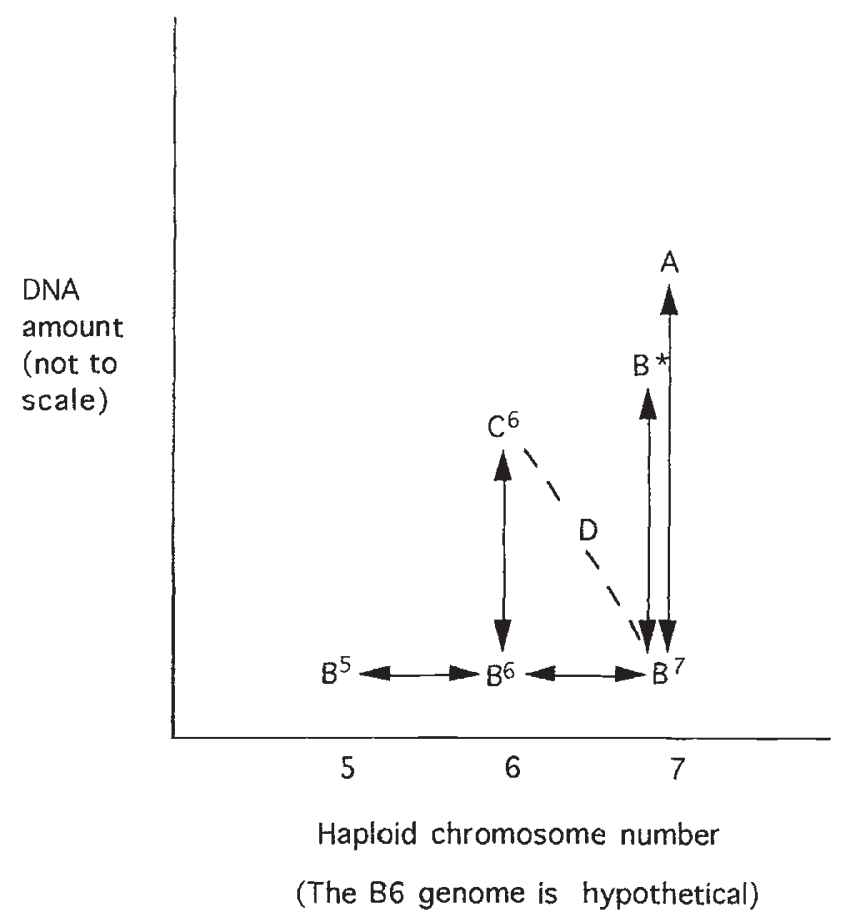

Fig. 5 Representation of the evolutionary relationships between diploid genomes of Scilla autumnalis, with an indication of change in DNA amount and haploid chromosome number. The $\mathrm{B}^{6}$ genome is hypothetical, its existence is suggested as the most parsimonious solution to the relationship of genomes. A possibility for the position of the $\mathrm{D}$ genome is also indicated in the scheme. This is intermediate in size between $\mathrm{B}^{7}$ and $\mathrm{C}^{6}$, with a chromosome number of 6 or 7 , and may have arisen from a polyploid $\mathrm{C}^{6} \mathrm{C}^{6} \mathrm{~B}^{7} \mathrm{~B}^{7}$ after recombination between genomes (see text).

(C) The Genetical Society of Great Britain, Heredity, 79, 371-379. 
and reunions. The most simple supposition is that it has only occurred once in the $S$. autumnalis lineage, giving rise to the $6 / 7$ fusion chromosomes apparent in genomes $\mathrm{B}^{5}$ and $\mathrm{C}^{6}$. An increase in DNA content subsequently occurred in $\mathrm{C}^{6}$ and a second fusion in $\mathrm{B}^{5}$, respectively. Thus an overall picture of genome evolution in $S$. autumnalis can be proposed as illustrated in Fig. 5.

\section{The diploid races of $\mathrm{S}$. autumnalis}

$B^{7} B^{7}, 2 \mathrm{n}=14$ These diploids are found in Crete, Greece, Cyprus, Spain, Sardinia, Sicily and Israel (Ainsworth et al., 1983). Their 2C DNA content is $11.5 \mathrm{pg}$.

$A A, 2 \mathrm{n}=14$ These diploids have been found in Spanish and Portuguese populations. DNA content of $2 \mathrm{C}$ nuclei is $17.0 \mathrm{pg}$.

$C^{6} C^{6}, 2 \mathrm{n}=12$ Populations of this type have only been found on Crete. DNA content of $2 \mathrm{C}$ nuclei is $14 \mathrm{pg}$.

$B^{5} B^{5}, 2 \mathrm{n}=10$ So far these populations have only been found in Libya. DNA content is $10 \mathrm{pg}$.

\section{Polyploid races of Scilla autumnalis}

$B^{7} B^{7} B^{7} B^{7}, 2 \mathrm{n}=28$ These autotetraploids carry four sets of the $B^{7}$ genome. Populations of this type have been found from the northern Mediterranean region (Greece and Turkey) as far north as southern England and including much of France. The distributions of tetraploid and diploid races overlap somewhat, for example in Sardinia, Corfu and southern Italy. No mixed diploid/tetraploid populations have yet been found.

$B^{7} B^{7} B^{7} B^{7} B^{7} B^{7}, 2 \mathrm{n}=42$ These carry six copies of the standard $B$ genome and have been described by Battaglia (1964) in populations from north-eastern Italy and by Baksay (1956) in populations from Hungary. In studies carried out in this laboratory autohexaploids have been found only as scattered individuals in tetraploid populations.

$A A B^{7} B^{7}, 2 \mathrm{n}=28 \quad$ Two copies of the $\mathrm{B}^{7}$ genome are present and two of the A genome, a classical allopolyploid (Fig. 2). The A genome differs from that in diploids by the absence of a secondary constriction. Thus chromosome A3 is almost indistinguishable from the metacentric chromosome A7. In addition there are slight differences in chromosome sizes and arm ratios between the A genome of allotetraploids and of diploids.

The allotetraploid race is endemic to the Iberian peninsula; populations of $\mathrm{AAB}^{7} \mathrm{~B}^{7}$ have been found in Portugal (Ainsworth et al., 1983), southern Spain and north-western Spain (Ruiz Rejón et al., 1980; Parker et al., 1991).

$A A B^{7} B^{7} B^{7} B^{7}, 2 \mathrm{n}=42$ This autoallohexaploid has four copies of the $\mathrm{B}^{7}$ genome and two of the A. As in the case of the allotetraploid $\mathrm{AAB}^{7} \mathrm{~B}^{7}$, the secondary constrictions are absent from chromosomes three of the A genomes whereas all nucleolar-organizer regions of the $\mathrm{B}^{7}$ homologues are expressed. The autoallohexaploids have a very limited distribution and have been discovered only in Cornwall, Devon, Guernsey and Sark.

$B^{7} B^{7} B^{*} B^{*}, 2 \mathrm{n}=28$ This contains two copies of the standard $B^{7}$ genome and a pair of genomes denoted $\mathrm{B}^{*}$, which are similar in size and morphology to $\mathrm{B}^{7}$ but in which the chromosomes appear longer, with slightly altered arm ratios (see above; Fig. 3.) In this tetraploid the secondary constriction of the NO-chromosome $\mathrm{B}^{*} 3$ is usually absent. In some plants the secondary constriction may be present but only faintly visible with Feulgen/LPO staining. More rarely it is clearly visible in most cells. By contrast the two NORs of the smaller genome are always visible by standard staining techniques. There appears to be no recombination between the two genomes as bivalents only are seen at metaphase I of meiosis.

$D D D D 24<2 \mathrm{n}<28$ There are a number of tetraploid populations in Crete in which balanced individuals may have between 24 and 28 chromosomes in somatic cells (Fig. 4.) The basic haploid set has either six or seven chromosomes. This is dependent on whether chromosomes 6 and 7 are present as single elements or as the fusion 6/7 (see the D genome above). The morphology of the NOR-bearing chromosome is variable and the number of NORs expressed also varies from one to four between individuals. Thus plants prove difficult to karyotype definitively because individual acrocentric chromosomes of groups 1,2 and 5 may not be distinguishable. Sometimes it appears that there are two larger and two smaller genomes present within an individual. Thus in a.set of four 'homologues' two are large and two small. It is possible that this tetraploid may have originated from two distinct diploid genomes, one of which may have been $\mathrm{B}^{7}$ and the other $C^{6}$. It is difficult to establish this because of 
the occurrence of recombination as evidenced by multivalents at metaphase I of meiosis. Alternatively, the progenitors could have been diploids $\mathrm{B}^{*} \mathrm{~B}^{*}$ and $\mathrm{B}^{6} \mathrm{~B}^{6}$. As chromosome sizes in these tetraploids are never as great as in the $\mathrm{B}^{*}$ genome, the former explanation is probably the more likely.

This race shows an almost continuous distribution both of DNA amount and of chromosome size over a larger range than any of the other races of $S$. autumnalis. Chromosomes from these plants are described as 'genome D', with a superscript of six or 7 to identify the number of chromosomes in each 'set'.

Populations of this cytotype have been found only in eastern Crete. No simple pattern of NOR expression is initially apparent in this cytotype. The tetraploids show from one to four NORs although usually two or three secondary constrictions are present. The NORs vary in the ease with which they can be detected in Feulgen-stained preparations.

\section{Discussion}

Scilla autumnalis, a bulbaceous perennial, is widespread around the Mediterranean, south-western England, Portugal, Libya and North Africa. Although described as a single species, this paper presents evidence that cryptic species exist. A vast amount of chromosomal variation is observed, some affecting a proportion of individuals within a population, and some affecting the whole genome, giving rise to distinct karyotypes. Ten such karyotypically distinct races are described here. Remarkably large differences in karyotype, C-value and ploidy level are found throughout the range of the species complex.

Four diploid karyotypes are described, which differ from one another by one or two chromosome fusion(s) and also by almost uniform increase in DNA amount over chromosomes of the whole complement. These karyotypes are remarkably uniform in morphology despite, in one case, a change in DNA amount of 68 per cent over the whole genome. The possibility of selection of symmetry within chromosome complements is considered. A suggestion is made for the evolution of diploid genomes, for which the existence, past or present, of a further diploid race, $\mathrm{B}^{6} \mathrm{~B}^{6}$, is postulated.

Karyotypes of polyploid races are made up from the same genomes described in the diploids in most cases. However, in one case, tetraploids $\mathrm{B}^{7} \mathrm{~B}^{7} \mathrm{~B}^{*} \mathrm{~B}^{*}$, the $\mathrm{B}^{*}$ genome is only found in the tetraploid described, not in diploids. An ancestral diploid,
$\mathrm{B}^{*} \mathrm{~B}^{*}$ is postulated. In the case of the Cretan race DDDD, it is difficult to determine the origin of the constituent genomes, but suggestions are made.

In summary, 10 distinct races of $S$. autumnalis have been described, involving chromosome rearrangements, changes in DNA amount, and polyploidy. Their distribution is shown in Fig. 6.

Crete has by far the most races for a given area, with $B^{7} B^{7}, C^{6} C^{6}$ diploids, $B^{7} B^{7} B^{*} B^{*}$ allotetraploids and DDDD tetraploid populations found on the island, as well as $\mathrm{B}^{7} \mathrm{C}^{6}$ hybrid individuals. It may be that Crete was a centre of expansion of the plant, and may also have comprised or been part of a glacial refugium during the last Ice Age. Indeed, geological pollen data as well as sequence data from insect nuclear and mitochondrial DNA suggest the existence of a Balkan/Greek refugium which could have involved Crete (Huntley \& Birks, 1983; Cooper et al., 1995). The large A genome has only been found to the west of the species range, and it may be that this genome evolved in the west or that it was isolated in a south-western refugium (Southern Spain) during the last Ice Age, and subsequently plants with this genome extended their range to Spain, Portugal, Sark and the west coast of Britain. In fact, several plant and invertebrate species are common to Iberia and the west coast of Britain, so called Lusitanian species. This could result from sea dispersal via the Gulf Stream, or even historical dispersal by man.

Polyploidy has also clearly played a role in the isolation of races of $S$. autumnalis. This is quite a common cause of reproductive isolation in the plant kingdom, and has been seen in many angiosperms (Hagberg \& Akerberg, 1962). For S. autumnalis several cases of autoploidy and alloploidy can be inferred. Unlike the examples involving karyotype change, this mechanism is relatively easy to envisage and can lead to immediate and sympatric isolation of forms.

Although the information presented is by no means comprehensive, the $\mathrm{B}^{7}$ tetraploid which covers most of the European mainland could have expanded from a Balkan refugium. It is possible to envisage a pattern of postglacial expansion which is similar to that described for some plant and invertebrate species (Cooper et al., 1995). Stebbins (1971) suggests that polyploids are at a selective advantage over diploids in habitats which have been subjected to frequent and extreme fluctuations in climate and edaphic factors. Certainly this could have been the case in mainland Europe, where hexaploids and tetraploids are found, compared with $\mathrm{B}^{7}$ diploids in the more southern island populations. However, 


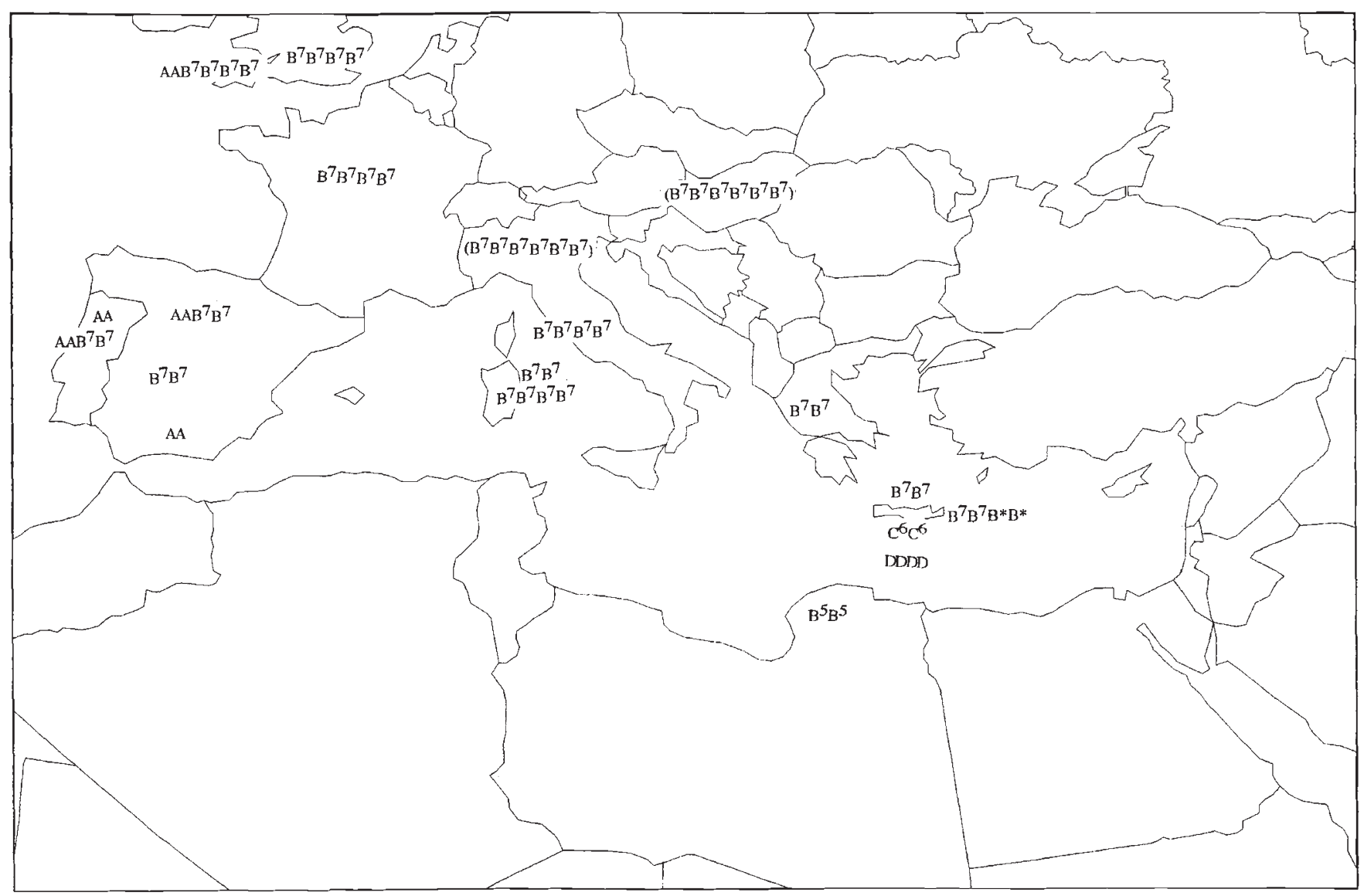

Fig. 6 Geographical distribution of the chromosomal races of the Scilla autumnalis species complex. Four of the 10 cytotypes are located in Crete; three of these $\left(C^{6} C^{6}\right.$, DDDD and $\left.B^{*} B^{*} B^{7} B^{7}\right)$ have only been found in Crete. Races in parentheses are those described by previous authors.

Darlington (1964) suggested that current distributions of ploidy levels are often merely a result of historical colonization; thus selection may not have contributed to the pattern seen today. Further work would have to be done on the system to determine any adaptive advantage of increasing nuclear DNA content by ploidy change or otherwise. Some examples of plant systems in which changing C-value correlates with other variables are given below.

The $\mathrm{B}^{*}$ genome, the larger of the two genomes in the $\mathrm{B}^{7} \mathrm{~B}^{7} \mathrm{~B}^{*} \mathrm{~B}^{*}$, has not been found in diploids. It is likely that this genome existed as a diploid which is currently undiscovered or extinct. It is possible that the constituent genomes of the DDDD race were $\mathrm{B}^{7}$ and either $\mathrm{B}^{6}$ or $\mathrm{C}^{6}$. Recombination between homoeologues has made the definitive identification of ancestral genomes impossible.

A schematic representation of the relationship of all genomes is shown in Fig. 5 .

The evolution of distinct genomes in the $S$. autumnalis complex implies isolation between the forms. Such isolation could have been spatial or reproductive, by temporal divergence of flowering, pollen/stylar incompatibility, or endosperm breakdown. The fact that many races produce fertile hybrids in the glasshouse suggests that isolation of forms is largely a result of allopatric divergence.

It is not clear how DNA changes per se could lead to the consequences of incompatibility described above, if indeed they do. Differences observed between genomes could be adaptive responses to different environments, or result from the accumulation of many 'neutral changes' in DNA amount. If the latter has occurred, it is possible that there has been simultaneous selection to maintain karyotype morphology over a broad range of $\mathrm{C}$-values (see below). With respect to selection for adaptive traits, it has been observed that in some plant species increases in nuclear DNA content are correlated positively or negatively with such parameters as seed mass, yield, growth indices, frost resistance, maturation and climatic factors (Wakamiya et al., 1993; 
Biradar et al., 1994; Creber et al., 1994; Graham et al., 1994; MacGillivray \& Grime, 1995). However, there does not seem to be a clear consensus regarding such results across a range of species. It has been demonstrated in maize that selection for early flowering time results in selection for smaller nuclear DNA content (Rayburn et al., 1994). Thus it seems feasible that the wide range of $\mathrm{C}$-values described here for Scilla could be selectively favoured by different environments. The environments encountered by $S$. autumnalis are indeed diverse, ranging from the relatively cold, wet parts of coastal Cornwall to dry inland regions of Israel and Libya. However, if selection were the sole cause of the variation, we would not expect such a massive variety of races on Crete, and such chromosomally diverse races in seemingly similar environments. Also, with respect to chromosome fusion, it is most likely that fusions $6 / 7$ and $1 / 3$ occurred just once, respectively, and sequentially, and were fixed because of drift.

Regarding the differences in DNA amount between diploid races alone, it is interesting that the karyotypes are so similar. Increase (decrease) in total nuclear DNA is achieved by roughly equivalent increments (decrements) in all chromosomes of the complement. This has also been documented across the genera Hypochoeris, Lathyrus, Lolium, Vicia and Festuca (C. G. See, personal communication; Narayan, 1983; Seal \& Rees, 1982; Raina \& Rees, 1983 ), and it has been proposed that there may be selection on the relative size of chromosomes within a complement (Raina \& Rees, 1983).

Morphology of individuals from all races is generally similar. Although cytotypes of $S$. autumnalis are often geographically isolated, many cross-fertilize in the glasshouse and $F_{1}$ progeny often exhibit perfect pairing recognition ( $\mathrm{S}$. Taylor, unpublished data), indicating that there is a significant part of the genome which has remained unchanged thoughout divergence. Thus only certain sequences of DNA change, often to an extraordinary extent, whereas other sequences vital to survival or reproduction remain constant and 'immune' to change. It is worth remembering that this paper represents only a proportion of the total chromosome variation that has been observed in S. autumnalis.

\section{Acknowledgements}

The research was funded by SERC (now BBSRC) and we would like to thank Professor G. M. Hewitt at the University of East Anglia for a preliminary reading of the manuscript.

\section{References}

AINSWORTH, C. C., PARKER, J. S. AND HORTON, D. M. 1983. Chromosome variation and evolution in Scilla autumnalis. In: Brandham, P. E. and Bennett, M. D. (eds) Kew Chromosome Conference II, pp. 261-268. George Allen \& Unwin, London

BAKSAY, L. 1956. Cytotaxonomical studies on the flora of Hungary. Ann. Hist. Nat. Mus. Nationalis Hungarica, 7, $321-334$.

BAtTAglia, E. 1964. Scilla autumnalis L: Recent investigations of the karyological biotypes $2 n, 4 n, 6 n$. Caryologia, 17, 557-565.

BHARATHAN, G., LAMBERT, G. AND GALBRAITH, D. w. 1994. Nuclear-DNA content of monocotyledons and related taxa. Am. J. Bot., 81, 381-386.

BIRADAR, D. P., BULlOCK, D. G. AND RAYBURN, A. L. 1994. Nuclear-DNA amount, growth, and yield parameters in maize Theor. Appl. Genet., 88, 557-560.

COATES, D. J. 1992. Genetic consequences of a bottleneck and spatial genetic structure in the triggerplant Stylidium coroniforme (Stylidiaceae). Heredity, 69, 512-520.

COLlins, F. H. AND PASKEWITZ, M. 1996. A review of the use of rDNA to differentiate among cryptic Anopheles species. Insect Mol. Biol., 5, 1-9.

COOPER, S. .. B., IBRAHIM, K. M. AND HEWITT, G. M. 1995. Postglacial expansion and genome subdivision in the European grasshopper, Chorthippus parallelus. Mol. Ecol., 4, 49-60.

CREBER, H. M. C., DAVIES, M. S., FRANCIS, D. AND WALKER, H. D. 1994. Variation in DNA C value in natural populations of Dactylis glomerata L. New Phytol., 128, 555-561.

DARlington, C. D. 1964. Chromosome Botany and the Origins of Cultivated Plants, 2nd edn. George Allen \& Unwin, London.

DAUGHeRTY, C. H., PATTERSON, G. B. AND hitCHMOUGH, R. A. 1994. Taxonomic and conservation review of the New Zealand Herpetofauna. N. Z. J. Zool., 21, 317-323.

GRAHAM, M. J., NICKELL, C. D. AND RAYBURN, A. L. 1994. Relationship between genome size and maturity group in soybean. Theor. Appl. Genet., 88, 429-432.

hagberg, A. And akerberg, E. 1962. Mutations and Polyploidy in Plant Breeding. Heinemann, London.

HUNTley, B. AND BIRKS, H. J. B. 1983. An Atlas of Past and Present Pollen Maps for Europe. Cambridge University Press, Cambridge.

KNIO, K. M., GOEDEN, R. D. AND HEADRICK, D. H. 1996. Descriptions of immature stages of Trupanea nigricornis and Trupanea bisetosa (Diptera, Tephritidae) from Southern California. Ann. Entomol. Soc. Am., 89, 1-11.

MACGILliVRAY, C. W., AND GRiME, J. P. 1995. Genome size predicts frost resistance in British herbaceous plants: implications for rates of vegetation response to global warming. Funct. Ecol., 9, 320-325.

MAYR, E. AND OHARA, R. J. 1986. The biogeographic evidence supporting the Pleistocene forest refuge hypothesis. Evolution, 40, 55-67.

NARAYAN, R. K. J. 1983. Chromosome changes in the 
evolution of Lathyrus species. In: Brandham, P. E. and Bennett, M. D. (eds) Kew Chromosome Conference II, pp. 243-250. George Allen \& Unwin, London.

.NEI, M. 1987. Molecular Evolutionary Genetics. Columbia University Press, New York.

PARKER, J. S., LOZANO, R., TAYLOR, S. AND RUIZ REJÓN, M. 1991. Chromosomal structure of populations of Scilla autumnalis in the Iberian peninsula. Heredity, 67, 287-297.

RAINA, S. N. AND REES, H. 1983. DNA variation between and within chromosome complements of Vicia species. Heredity, 51, 335-346.

RAYBURN, A. L., DUDLEY, J. W. AND BIRADAR, D. P. 1994. Selection for early flowering results in simultaneous selection for reduced nuclear DNA content in maize. Plant Breeding-Zeitschrift für Pflanzenzüchtung, 112, 318-322.
RUIZ REJÓN, M., OLIVER, J. L. AND RUIZ REJÓN, C. 1980. Variabilidad cromosomica en Scilla autumnalis L. (Liliaceae) de la Penninsula Iberica. Boletim da Soc. Broteriana, LIII, 555-562.

SEAL, A. G. AND REES, H. 1982. The distribution of quantitative DNA changes associated with the evolution of diploid Festuceae. Heredity, 49, 179-190.

STEBbins, G. L. 1971. Chromosomal Evolution in Higher Plants. Edward Arnold, London.

VAUGHAN, H. E., Jamilena, M., RUiz REJón, C., PARKeR, J. S. AND GARRIDO-RAMOS, M. A. 1993. Loss of nucleolarorganizer regions during polyploid evolution in Scilla autumnalis. Heredity, 71, 574-580.

WAKAMIYA, I., NEWTON, R. J., JOHNSTON, J. S. AND PRICE, H. J. 1993. Genome size and environmental factors in the genus Pinus. Am. J. Bot., 80, 1235-1241. 